\title{
Perancangan PLTA Pico-Hydro menggunakan Tabung Hydrocyclone dan Turbin Kaplan melalui Solusi Numerik Runge-Kutta
}

\author{
Indah Permatasari*1 dan Abdul Hakim Prima Yuniarto ${ }^{2}$ \\ ${ }^{1}$ Institut Teknologi Telkom Purwokerto, Jl.D.I.Panjaitan No.128, Purwokerto 53147 \\ ${ }^{2}$ Institut Teknologi dan Sains Nahdlatul Ulama (ITS NU) Pekalongan, Jl. Karangdowo No.9, Pekalongan 51173
}

Intisari

\begin{abstract}
Perancangan PLTA Pico-Hydro menggunakan turbin Kaplan dilakukan dengan memanfaatkan aliran air berbentuk tabung Hydrocyclone. Turbin Kaplan dapat bergerak dengan kecepatan putaran mengikuti kecepatan rotasi fluida sehingga dapat dianalisis sistem gerak konverternya. Perumusan persamaan gerak yang diperoleh melalui penerapan persamaan Euler-Lagrange untuk menghasilkan persamaan diferensial. Persamaan tersebut diterapkan dengan metode Runge-Kutta yang merupakan salah satu metode pendekatan iterasi dengan solusi numerik. Sistem konverter gerak initerdiri dari 5 roda dengan roda ke-1 seporos dengan roda ke-2. Roda ke-2 dan ke-3 terhubung secara serantai dan roda ke-4 saling terhubung dengan roda ke-5 untuk menghasilkan pembangkit listrik. Hasil yang diperoleh aliran air dapat memutarkan turbin kaplan dengan gaya sebesar $50 \mathrm{~N}$. Kecepatan putaran sudut maksimum sebesar $5500 \mathrm{rad} / \mathrm{s}$ pada roda ke-5. Kecepatan putaran roda-roda pada sistem konverter akan semakin meningkat seiring dengan bertambahnya waktu.
\end{abstract}

\begin{abstract}
Designing of the Pico-hydrowater Power Plan which uses Kaplan turbine applies water flow within Hydrocyclone tube. Kaplan turbines can move with angular velocity following fluid velocity analyzing the movement converter system. Equation of movement formulated by applying Euler-Lagrange, therefore, generating a differential equation. The differential equation iterated by the Runge-Kutta Method which is one of the numerical solutions. The movement converter system consists of 5 wheels with 1 st wheel spindle with $2^{\text {nd }}$ wheel. The $2^{\text {nd }}$ and $3^{\text {rd }}$ wheels are interconnected and the $4^{\text {th }}$ wheel is connected to the 5 th wheel to generate electricity generation. The results obtained by the flow of water can rotate Kaplan turbines with a force of 50N. Maximum angular velocity of $5500 \mathrm{rad} / \mathrm{s}$ on the 5 th wheel. The rotation speed of the wheels on the converter system will increase with time.
\end{abstract}

Keywords: angular velocity; hydrocyclone; Kaplan turbine; pico-hydro.

*Corresponding author: indah@ittelkom-pwt.ac.id

http://dx.doi.org/10.12962/j24604682.v16i1.5782

2460-4682 @DDepartemen Fisika, FSAD-ITS

\section{PENDAHULUAN}

Ketersediaan pasokan listrik di pedesaan merupakan salah satu kebutuhan yang sangat penting guna menunjang kualitas hidup masyarakat. Permasalahan bagi daerah di pedesaan yang belum mendapatkan pelayanan listrik dari PLN (Perusahaan Listrik Negara), biasanya diatasi dengan pembuatan Pembangkit Listrik Tenaga Air (PLTA) skala kecil atau PLTA Pico-Hydro. PLTA Pico-Hydro merupakan salah satu sistem untuk mengkonversi energi dari air menjadi energi listrik yang bisa diperbarui [1]. Persyaratan yang harus dipenuhi dalam pengembangan sistem ini adalah ketersediaan aliran air bertekanan tinggi dalam bentuk aliran sungai atau air terjun skala kecil dengan kecepatan arus yang memadai [2]. Jika kondisi ini tidak terpenuhi, maka hal ini akan menjadi masalah tersendiri bagi wilayah di pedesaan yang tidak mempunyai sumber aliran yang memadai. Untuk itu, dibuat sebuah inovasi untuk mengatasi persoalan ini melalui perancangan dan realisasi PLTA Pico-Hydro yang mampu bekerja dalam kondisi kecepatan aliran air yang tidak memadai.

Inovasi ini dikembangkan dengan memanfaatkan aliran air dalam bak penampungan berbentuk tabung hydrocyclone dengan bagian bawahnya berbentuk kerucut. Bagian bawah bak tersebut dibuat sebuah lubang untuk mengalirkan air dari bagian atas ke bagian bawah. Berdasarkan prinsip mekanika fluida jika sebuah sistem mendapatkan tekanan dari atas, maka gerakan fluida atau air tersebut akan mengalir dan membentuk gerak rotasional jika bagian bawah lebih sempit dari bagian atas [3]. Efek rotasional ini dapat dimanfaatkan untuk memutar turbin Kaplan. Turbin Kaplan merupakan salah satu jenis turbin yang bentuknya sangat popular seperti baling-baling pesawat dan kapal laut [4]. Turbin Kaplan dapat bergerak 
dengan kecepatan putaran mengikuti kecepatan rotasi fluida yang dalam hal ini adalah aliran rotasional air pada bagian bawah bak penampungan.

Perumusan persamaan gerak diperoleh melalui persamaan Euler-Lagrange untuk menganalisis putaran konverter pada turbin Kaplan. Penerapan persamaan Euler-Lagrange telah berhasil diterapkan untuk menganalisis putaran roda pada sepeda sebagai representasi gerak giroskop [5]. Perumusan persamaan gerak yang diperoleh melalui penerapan persamaan Euler-Lagrange dalam bentuk persamaan diferensial. Permalasahan yang terdapat dalam persamaan diferensial tidak dapat diselesaikan secara analitik sehingga membutuhkan penyelesaian secara numerik [6]. Untuk mengetahui beberapa besaran fisis yang terkait dengan sistem yang akan ditinjau, maka pada penelitian ini dilakukan penentuan solusi numerik persamaan gerak sistem konverter dengan metode Runge-Kutta. Metode Runge Kutta adalah metode penyelesaian masalah nilai awal persamaan differensial dengan pendekatan iterasi numerik sehingga dilakukan dengan pemprograman computer [7].

Perhitungan algoritma dengan metode Runge-Kutta dari fungsi Lagrange terdiri atas inersia dan jari-jari roda akan dilakukan untukmenghitung kecepatan putaran roda dan ukuran roda-roda yang menghubungkan antara turbin dan generator. Tujuan penelitian ini untuk menentukan ukuran jari-jari pada roda sehingga dapat menghasilkan sistem konverter yang ideal dan penentuan parameter gaya dan momen inersia pada turbin Kaplan.

\section{METODOLOGI}

Tahapan pertama pada penelitian ini adalah penentuan dimensi dan ukuran tabung hydrocyclone dan turbin Kaplan melalui percobaan beberapa ukuran tabung dan turbin yang mampu menghasilkan gerak rotasional untuk memutarkan poros turbin dengan kecepatan sudut $(\omega)$. Bentuk turbin dimodifikasi dari bentuk dasarnya agar diperoleh putaran yang optimal. Parameter yang terkait dengan dimensi tabung dan turbin adalah: tingggi tabung $(\mathrm{H})$, tinggi kerucut $(\mathrm{h})$, diameter tabung (D), jari-jari turbin (r) dan sudut pada sisi-sisi kerucut $(\theta)$. Berikut merupakan desain tabung hydrocyclone dan turbin kaplan seperti ditunjukkan Gambar 1.

Tahapan ini melakukan penentuan dimensi ukuran tabung hydrocyclone dengan menggunakan persamaan matematis turbin air jenis Kaplan sebagai berikut:

$$
Q=k \sqrt{2 g h} \frac{\pi}{4} D^{2}
$$

Pada turbin kaplan ini sudut sudu pengarah sebesar $30^{\circ}$ karena dapat menghasilkan putaran yang maksimal. Nilai debit air yang dihasilkan agar air dapat bergerak rotasional maka tinggi kerucut $(\mathrm{H})=15 \mathrm{~cm}$, tinggi tabung $(\mathrm{h})=19,5 \mathrm{~cm}$ dan diameter tabung $(\mathrm{D})=19 \mathrm{~cm}$.

Langkah selanjutnya penyelesaian perumusan persamaan gerak PLTA Pico-Hydro adalah dengan mencari torsi pada titik pusat massa roda 1 . Titik pusat massa roda 1 terletak pada sumbu putarnya sehingga jarak titik pusat massa roda

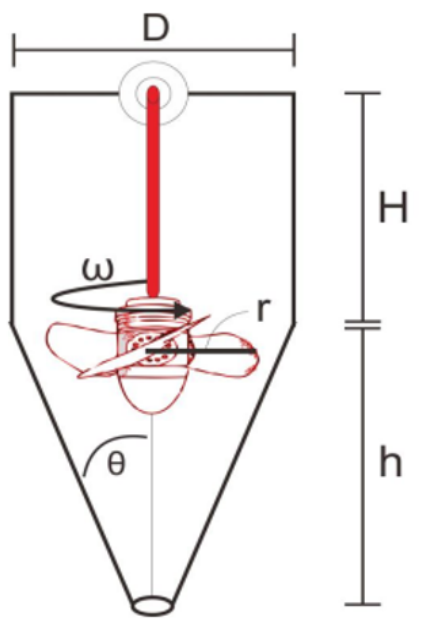

Gambar 1: Skema tabung hydrocyclone dan turbin Kaplan.

pertama adalah jari-jarinya. Torsi pada roda 1 yang dikenai gaya $\mathrm{F}$ tegak lurus dapat dirumuskan sebagai berikut:

$$
\tau=F \dot{r}_{1} \sin 90
$$

Pers.(2) adalah gaya eksternal berupa torsi pada titik pusat massa, yaitu gaya yang melawan gerakan sistem konverter untuk berputar, serta gaya gesekan yang bergantung pada frekuensi anguler turbin yang terkopel serta bergantung pada suatu konstanta $\mathrm{b}$ atau koefisien gesekan kinetis $\theta_{1} b$ termasuk gaya eksternalnya juga. Maka $\mathrm{Q}_{n}$ dalam persamaan EulerLagrange dapat dirumuskan sebagai berikut:

$$
Q_{n}=F R_{1}-\dot{\theta_{1}}
$$

Sistem konverter ini hanya berputar pada poros yang tetap, maka energi potensialnya dianggap tidak ada $\mathrm{V}=0$. Komponen PLTA Picohydro yang terdiri atas 5 roda dengan energi kinetik rotasi yang dirumuskan sebagai berikut:

$$
T=\frac{1}{2} I_{1} \dot{\theta}^{2}
$$

Maka perumusan fungsi Lagrange yang tersusun dari $\mathrm{V}=0$ dan $\mathrm{T}$ adalah sebagai berikut:

$$
L=\frac{\dot{\theta_{1}^{2}}}{2}\left[I_{1}+I_{2}\left(\frac{r_{1}}{r_{2}}\right)^{2}+I_{3}\left(\frac{r_{1}}{r_{2}}\right)^{2}+I_{4}\left(\frac{r_{1} r_{3}}{r_{2} r_{4}}\right)^{2}+I_{5}\left(\frac{r_{1} r_{3}}{r_{2} r_{4}}\right)^{2}\right]
$$




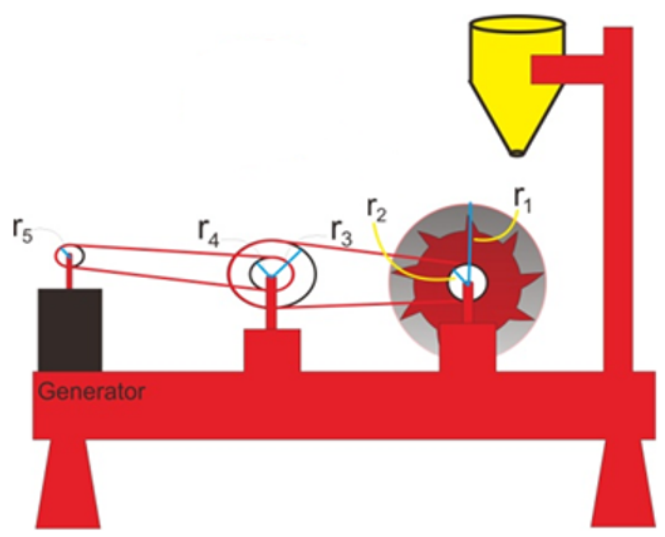

Gambar 2: Sistem konverter yang dirancang.

Kecepatan putaran setiap roda dapat dirumuskan sebagai berikut:

$$
\begin{aligned}
\dot{\theta} & =\dot{\theta}_{3}=\dot{\theta}_{1}\left(\frac{r_{1}}{r_{2}}\right) \\
\dot{\theta}_{4} & =\dot{\theta}_{5}=\dot{\theta}_{1}\left(\frac{r_{1} r_{3}}{r_{2} r_{4}}\right)
\end{aligned}
$$

Maka persamaan gerak konverter energi PLTA Picohydro dapat dinyatakan dengan dalam perumusan sederhana, yaitu:

$$
\frac{d^{2} \dot{\theta}_{1}}{d t^{2}}=\frac{F r_{1}-\dot{\theta}_{1} b}{I}
$$

Setelah mendapatkan perumusan matematis dari persamaan gerak maka langkah selajutnya melakukan simulasi dengan program Matlab dengan metode Runge-Kutta. Hasil tersebut kemudian akan diimplementasikan dalam pembuatan prototype.

\section{HASIL DAN PEMBAHASAN}

Persamaan gerak sistem PLTA Pico-Hydro diselesaikan dengan menggunakan metode Runge-Kutta orde-4. Diasumsikan bahwa dorongan air yang keluar dari ujung tabung $h y$ drocyclone dinyatakan dalam bentuk $\mathrm{F}$ merupakan gaya eksternal. Gaya tersebut bernilai konstan pada rentang waktu cukup lama kemudian bernilai nol pada rentang waktu yang sedikit. Algoritma diperoleh dengan metode Runge-Kutta untuk menentukan solusi numerik persamaan gerak konverter energi PLTA Pico-Hydro.

Prinsip kerja pembangkit listrik tenaga air picohydro dapat menghasilkan listrik dari aliran air, ketika aliran air memutarkan turbin, maka roda-roda berputar dengan generator dan dapat menghasilkan listrik. Sistem roda terdiri atas roda seporos dan serantai yang keduanya akan saling terhubung dan digunakan untuk menghasilkan pembangkit yang memiliki kecepatan anguler optimal. Roda pertama seporos dengan roda ke-2. Roda ke-2 dengan roda ke-3 terhubung secara serantai. Selanjutnya, roda ke-3 dan 4 dihubungkan dengan sis-

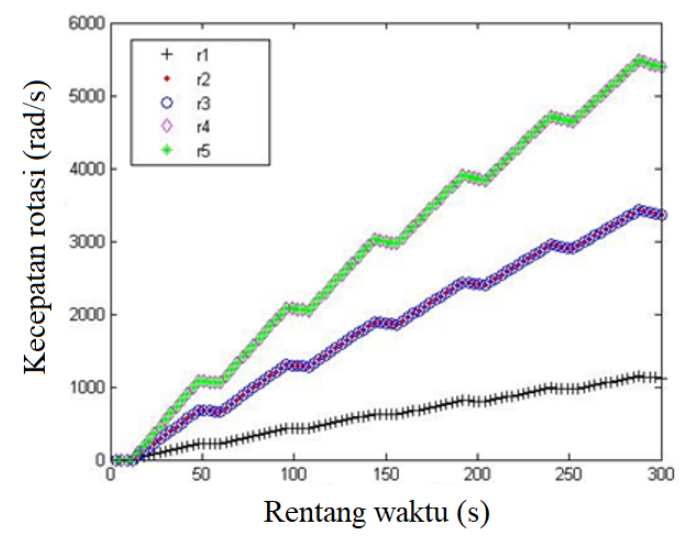

Gambar 3: Grafik karakteristik putaran roda yang ideal setelah mendapatkan gaya sebesar $50 \mathrm{~N}$.

tem roda yang seporos. Roda ke-4 dengan 5 dihubungkan serantai, dan roda 5 dihubungkan dengan generator. Gambar 2 menunjukkan desain sistem konverter yang dirancang.

Metode Runge Kutta diselesaikan dengan komputasi karena dapat menyederhanakan persoalan matematis untuk menyelesaikan persamaan diferensial yang didapatkan seperti pada Pers.(8). Adapun untuk memperoleh parameter jari-jari roda dan momen inersia melalui metode Runge Kutta orde 4 ini dapat dinyatakan dalam persamaan berikut ini:

$$
y_{(}(i+1)=y_{i}+\frac{1}{6} k_{1}+2 k_{2}+2 k_{3}+k_{4}
$$

Hasil perhitungan menunjukkan jari-jari roda $\mathrm{r}_{1}=0,9 \mathrm{~m}, \mathrm{r}_{2}$ $=0,3 \mathrm{~m}, \mathrm{r}_{3}=0,8 \mathrm{~m}, \mathrm{r}_{4}=0,5 \mathrm{~m}, \mathrm{r}_{5}=0,2 \mathrm{~m}$. Nilai jari-jari roda tersebut mampu memutarkan turbin ketika dikenai gaya sebesar 50 N. Sumbu putar roda mampu menggerakkan roda melalui titik pusat roda. Dimana momen inersia pada titik pusat roda diperoleh dari $\mathrm{I}=\mathrm{m} \cdot \mathrm{r}^{2}$ dengan massa roda berbedaberbeda. Semakin besar nilai momen inersianya maka jarak pusat roda semakin besar. Inersia masing-masing roda secara berturut-turut adalah 0,$5 ; 0,02 ; 0,245 ; 0,18$; dan $0,05 \mathrm{kgm}^{2}$. Berdasarkan parameter tersebut maka diperoleh hasil perhitungan numerik yang menunjukkan karakteristik kecepatan putaran roda-roda dalam satuan radian/second seperti ditunjukkan Gambar 3.

Berdasarkan grafik karakteristik dalam Gambar 3 diperoleh kecepatan putaran roda-roda terhadap waktu pada sistem konverter energi Pico-Hydro. Iterasi dilakukan sebanyak 100 sehingga diperoleh nilai eror yang kecil sebesar 0,08. Roda pertama dengan kecepatan $1000 \mathrm{rad} / \mathrm{s}$ terkena dorongan air langsung keluar dari tabung hydrocyclone. Roda 2 dan 3 yang terhubung serantai memiliki kecepatan sudut optimalnya $3600 \mathrm{rad} / \mathrm{s}$ kemudian roda 4 dan 5 terhubung satu dengan lainnya memiliki kecepatan yang besar dibandingkan dengan roda yang lain yaitu $5500 \mathrm{rad} / \mathrm{s}$. Berdasarkan hasil tersebut sistem konverter ini dapat berkerja dengan baik ditunjukkan dengan semula bergerak lambat mampu mempercepat putaran roda 5 yang terhubung dengan genetor listrik. Gaya yang didapatkan sebesar $50 \mathrm{~N}$ untuk putaran roda-roda yang terhubung oleh turbin kaplan. Hasil ini berbeda dengan hasil penelitian yang 


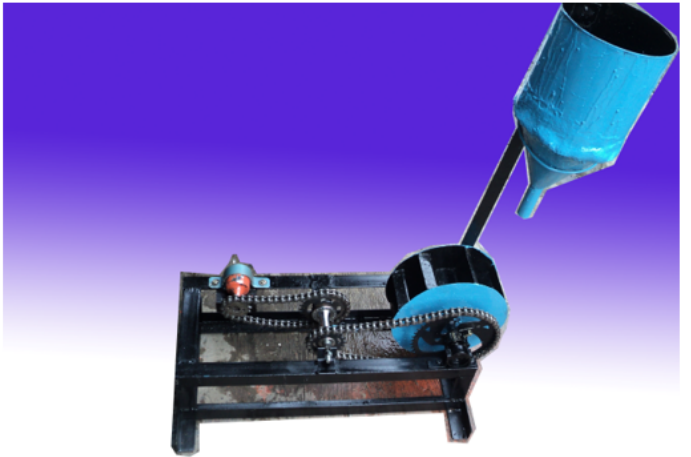

Gambar 4: Prototype PLTA Pico-hydro.

dilakukan oleh Saputra (2018) menunjukkan gaya untuk poros turbin kaplan sebesar 53,9 N [8]. Semakin besar kecepatan sudut putaran roda-roda seiring dengan bertambahnya waktu.
Hasil tersebut kemudian diimplementasikan ke dalam pembuatan prototype yang ditunjukkan pada Gambar 4.

Realisasi PLTA dengan pembuatan prototype skala Picohydro kemudian dilakukan pengujian dengan menggunakan lampu 3 Watt. Pada saat tabung hydrocyclone dialiri air maka aliran air tersebut akan menggerakan turbin kaplan yang terintegrasikan ke dalam roda-roda yang saling bergerak satu sama lain sehingga dapat menghasilkan listrik pada lampu dengan daya sebesar 3 Watt.

\section{SIMPULAN}

Putaran roda-roda berdasarkan metode Runge-Kutta diperoleh nilai jari-jari roda $1,2,3$, 4, dan 5 masing-masing 0,9 ; 0,$3 ; 0,8 ; 0,5$; dan $0,2 \mathrm{~m}$. Gaya yang didapatkan sebesar $50 \mathrm{~N}$ dengan kecepatan sudut maksimum sebesar $5500 \mathrm{rad} / \mathrm{s}$ untuk putaran roda 5 yang terhubung ke generator.
[1] E. Suryono, "Simulasi Turbin Crossflow Dengan Jumlah Sudu 18 Sebagai Pembangkit Listrik Picohydro", SIMETRIS, vol. 8, no. 2, pp. 547-552, November 2017.

[2] K. Alexander and E. Giddens, "Optimum Penstocks For Low Head Microhydro Schemes", Renewable Energy, vol. 33, no. 3, pp. 507-519, March 2008

[3] S. Klara, "Mechanic Fluid Dynamic", Makasar: LKPP, 2011.

[4] J.B. Sinaga, "Perancangan Turbin Air Untuk Sistem Pembangkit Listrik Tenaga Mikro Hidro (Studi Kasus Desa Way Gison Kecamatan Sekincau Kabupaten Lampung Barat)", Jurnal Sains dan Inovasi, vol. 16, no. 2, pp. 1-12, 2009.

[5] J. Meijaard, "Linearized Dynamics Equations For The Balance And Steer Of A Bicycle: A Benchmark And Review", in Pro- ceedings of The Royal Society Of London A: Mathematical Physical and Engineering Science, 2007.

[6] Z.M. Mayasari, Y. Fauzi and C.R.P. Jelita, "Kajian Solusi Numerik Metode Runge Kutta Nystrom Orde Empat Dalam Menyelesaikan Persamaan Differensial Liniear Homogen Orde Dua", Gradien, vol. 12, no. 2, pp. 1165-1170, April 2016.

[7] H. Wijayanti, S. Setyaningsih and M. Wati, "Metode Runge Kutta Dalam Penyelesaian Model Radang Akut", Ekologia, vol. 11, no. 2, pp. 46-52, Oktober 2011.

[8] R. Saputra and T. Liichan, "Perancangan Ulang Turbin Kaplan Poros Vertikal di PLTM Plumbungan", Bina Teknika, vol. 14, no. 2, pp. 153-161, Desember 2018. 